\title{
Training Needs Assessment for Nurses in Sennar State, Sudan: Cross Sectional Study (1)
}

\author{
Nada Mohamed Ali Alnair ${ }^{1, ~ *, ~ E l f a t i h ~ M o h a m e d ~ M a l i k ~}{ }^{2}$, Malaz Elbashir Ahmed ${ }^{3}$, \\ Ibrahim Ismail Mohamed $\mathrm{Abu}^{4,5}$
}

${ }^{1}$ Federal Ministry of Health, Continuous Professional Development Directorate, Khartoum, Sudan

${ }^{2}$ Community Medicine Department, Faculty of Medicine, University of Khartoum, Khartoum, Sudan

${ }^{3}$ Community Medicine, Federal Ministry of Health, Khartoum, Sudan

${ }^{4}$ Community Medicine Department, Faculty of Medicine, King Abdul-Aziz University, Al Fashir, Sudan

${ }^{5}$ Kingdom of Saudi Arabia \&Community Medicine Department, Faculty of Medicine, Al Fashir University, Al Fashir, Sudan

\section{Email Address:}

nadaalnayer@gmail.com (N.M. A. Alnair), fatihmmalik@hotmail.com (E. M. Malik), malazelbashir@gmail.com (M. E. Ahmed), burha75@gmail.com (I. I. M. Abu)

${ }^{*}$ Corresponding author

\section{To cite this article:}

Nada Mohamed Ali Alnair, Elfatih Mohamed Malik, Malaz Elbashir Ahmed, Ibrahim Ismail Mohamed Abu. Training Needs Assessment for Nurses in Sennar State, Sudan: Cross Sectional Study (1). Science Journal of Public Health. Vol. 7, No. 4, 2019, pp. 104-114. doi: $10.11648 /$ j.sjph.20190704.11

Received: February 26, 2019; Accepted: April 12, 2019; Published: July 12, 2019

\begin{abstract}
Continuous professional development for all health care providers including nurses is vital to be updated and able to provide quality services. All types of continuing professional development programs are often described as a cycle. This cycle is composed of interrelated components that are the steps of a systematic process, usually starting with identifying learning needs and ending with assessing learning and training evaluation. Training Needs Assessment (TNA) is a method to determine performance gaps, and what training is required to fill in these gaps. Appropriate use of TNA can prevent unnecessary spending on improper, inefficient, and/or ill-targeted training programs, and maintain more focus on the real needs. It also helps save time and resources. The following paper will address the issue of TNA and its accompanying paper will consider the issue of training evaluation in Sudan. The study overall objective was to assess training needs among nurses in Sennar and Singa hospital and to compare the results. Specific objectives were: to identify training needs from viewpoint of nurses, doctors and sisters as well as to develop need-based training module. It was descriptive cross sectional study. A total of 173 nurses, 15 sisters and 13 doctors participated in the need assessment survey. Survey results showed that most of nurses had not attended any in-service training. There were clear gaps in equipment using, task performance, communication and ethical issues. The most important training needs were infection control, communication, ethics, and nursing emergency. Infection control training manual was developed accordingly. There were real and conceptual training needs for nurses identified by nurses, sisters and doctors. All of these training gaps and needs should be considered in the development of future training modules for nurses in Sennar State. In the future, continuous professional development should be promoted through sound evidence-based planning, which means that TNA must be an activity that precedes the preparation and implementation of training programs. Delivering training with the career path so that each nurse has the training opportunity is also strongly recommended as well as fair distribution of training opportunities in the state.
\end{abstract}

Keywords: Training Needs Assessment, Needs Assessment, Training, Training Evaluation, Nurses

\section{Introduction}

Training of human Resources for Health (HRH) and practice were deeply rooted in Sudan, which is regarded as a pioneering country in the continent. Educational and management work over years has culminated into a health workforce that is composed of more than 100 thousand health workers making over 20 different professions [1]. The 
picture of Sudan nursing workforce today shows dominance of females representing more than half but with increasing trends. The age structure points to a rather young nurses probably due to the recent expansion in medical and health profession education [1].

The Ministry of Higher Education is responsible for preservice training and production of nurses through nursing schools and health training institutes [1]. As a result of the Sudan Declaration (2001) for up-grading the paramedics, the Ministry of Health established the Academy of Health Sciences (AHS) in 2005. Accordingly, all the old training schools and institutes that were affiliated to the Federal Ministry of Health (FMOH) are now under the umbrella of the AHS, including all the nursing schools, midwifery schools, paramedics training institutes [2]. Now the AHS has 15 main branches, one in each state with some states have some other training sites at main cities. The academies now enrolled about 15,300 students, $80 \%$ of them are nurses and graduated about 1,727 cadres from different programs, e.g. nursing (diploma) and upgrading (BSc.) according to AHS statistics in 2010. Consequently, there are 4 different undergraduate nursing programs in Sudan; three years' diploma (nurse technicians), two years bridging program to upgrade the three years' program to $\mathrm{BSc}$, four years BSc (professional nurses/sisters) and five years' honor BSc [2].

The National Council for medical and health Professions is entrusted with registration and licensing of nursing workforces [1]. The Federal Ministry of Health and the State Ministries of Health are the major employers responsible for nurse's management and in service development. The HRH national survey conducted in 2006 had shown that three quarters of the country health workforce $(74 \%)$ did not receive any form of in-service structured training during the past 5 years. The few staff that had the chance to attend Continuous Professional Development (CPD) programs is mostly confined to urban areas and predominantly belongs to the medical profession. In rural areas, it is common to find health workers who have not been refreshed for periods of 15 years or more [1]. As a result of that, Continuous Professional Development Centre (CPDC) is established with 25 main branches established in states and hospitals [3]. Now, there are 18 branches in all states due to increase in the number of states. The Continuous Professional Development Directorate (CPDD) has progressed very well in issues related to finalization of the CPD policy, strategy, improving the quality and expansion of activities, fostering partnership, and strengthening the state branches and developing the elearning system. Nevertheless, the current practices of CPD in Sudan are fragmented and lacking coordination, which demand a patent system for need assessment and impact evaluation [4]. And the idea of CPD is not well understood among health professionals [5]. The culture and attitude of continuing learning and self-development amongst health professionals are considered poor in Sudan [6].

All types of continuing professional development programs are often described as a cycle. This cycle refers to the process of continuous improvement, both in terms of training processes and in terms of the professional development of learners. This cycle is composed of interrelated components that are the steps of a systematic process, usually starting with identifying learning needs and ending with assessing learning and training evaluation. The CPDD is mandated to develop wide - range of in-service curricula, guidelines and Standard Operational Procedures (SOPs) for health personnel. However, training should follow all steps of the training cycle from needs assessment to evaluation which is not the case in Sudan now. TNA is the approach supposed to be introduced unduly for this purpose. Appropriate use of TNA can prevent unnecessary spending on improper, inefficient, and/or ill-targeted training programs, and maintain more focus on the real needs. It also helps save time and resources as well as having good impact on the performance [7]. Therefore, this study is aimed to study CPD for nurses in Sudan. This work will be presented in series of papers. This paper considers the TNA and intended to assess the training needs for nurses in Sennar state.

\section{Materials and Methods}

\subsection{Study Design}

In this paper we will address only the first stage which is descriptive cross sectional study. However, the whole study is a quasi-experimental one, composed of four stages, namely (i) a baseline survey in the two selected hospitals to assess the training needs of nurses; (ii) pre-assessment of status of nurses' knowledge, attitude and practices (KAP); (iii) training of nurses (study intervention); and (iv) postintervention assessment 3-month later.

\subsection{Study Area/Setting}

Sennar State has an area of $37,844 \mathrm{~km}^{2}$ and approximately 1.1 million populations; the State has 8 localities and its capital town is Singa, while Sennar is the second town. There are two main Teaching Hospitals in each of Sennar and Singa towns, which are both serving the Faculty of Medicine of Sennar University. The 2015 annual frequency rate was 76,998 in Sennar Teaching Hospital with 490 beds. For the same period, the annual frequency rate in Singa Teaching Hospital was 79,774 with 169 beds.

\subsection{Study Population/Subjects}

The study population composed of three categories of health cadres, as follows:

Nurses:

Inclusion criteria: all nurses in Sennar and Singa Hospitals who have nursing certificate, diploma or bridging courses were included in the study.

Exclusion criteria: nurses who were under training and those enrolled for National Service were excluded in the study.

Sisters:

Inclusion criteria: all sisters in Sennar and Singa Hospitals who hold 4-year bachelor degree in nursing studies were 
included in the study.

Exclusion criteria: all sisters with work experience for less than 3-month period in the specific hospital, and sister midwives were all excluded in the study.

Doctors:

Inclusion criteria: all doctors (medicals and consultants) working in Sennar and Singa hospitals were included in the study.

Exclusion criteria: doctors with work experience for less than 3-month period in the specific hospital, registrars and house officers were all excluded in the study.

\subsection{Sample Size and Sampling Technique}

The sampling technique was total coverage for the nurses in Sennar and Singa Hospitals. The total number of nurses in Sennar hospital was 122 nurses out of which 110 nurses accepted to participate in the study (90.2\% response rate), while 2 nurses refused to participate and the other 10 were on annual leave. In Singa Hospital, 63 out of the total number of 68 nurses accepted to participate in the study $(92.6 \%$ response rate), while the remaining other 5 candidates were on annual leave. This made the sample of the total coverage at 173 nurses. Convenient sampling technique was used for sisters in Sennar and Singa Hospitals. Out of the total number of 10 sisters in Sennar Hospital, 7 of them participated in the Focus Group Discussion (FGD), while one sister refused to participate, another one had severely ill patient at the time of the FGD and the third one was on maternity leave. In Singa Hospital, all of the 8 sisters participated in the FGD. This made a total number to 15 sisters participated in the two FGDs conducted (one in each Hospital).

As for doctors in the two Hospitals, satisfaction sampling technique was used, where 13 doctors in the two hospitals out of the total number of 102 doctors were interviewed.

\subsection{Data Collection Tools}

A structured questionnaire was used for data collection from nurses. The questionnaire was a standardized one developed by Jayne Fraser a training manager and adapted by the researcher according to the context in Sudan. The questionnaire adopted the job-task analysis modality based on job description. In this study, the job description for nurses was obtained from Sudan Council for Allied Professions, containing 12 tasks. Each task had been rated along 4-point scale according to two criteria: how important the task is to the successful performance of the respondent's job; and how well the respondent is currently performing the task, a comparison of the two ratings on any item provides an assessment of the training need associated with the task. When a task ranks as highly important but is not wellperformed, this means there is a need for training. Similarly, when a task that ranks less important or is well-performed, this means that there is no need for training. The training needs are then prioritized so as to identify the ones in most need for development. Such importance/performance comparison is well established as a reliable technique to identify training needs. Semi-structured in-depth interviews tool was used for data collection from the Doctors (medicals and consultants). Interview questions were developed by the researcher around four main themes (CPD concept, previous training courses conducted for nurses, challenges encountered and challenges for the training of nurses in general, and training needs for nurses. FGDs were used for data collection from the sisters using specific FGD-guide. The discussion was around four main themes (communication and leadership skills, basic nursing skills, nursing ethics and nurses training needs or gaps). All data collection tools were tested and piloted before actual data collection. Tools were piloted at Ibrahim Malik Hospital in Khartoum and were modified accordingly.

\subsection{Data Collection Techniques}

Interviewing:

A structured questionnaire was used to collect data from nurses, the data collection conducted by the researcher and one data collector who was trained before conducting the fieldwork.

Focus group discussion:

The FGD was carried out by the researcher and one assistant. Two FGDs were conduct, one in Sennar Hospital and the other one was in Singa Hospital. The researcher took the responsibility of leading the discussion; the assistant took the responsibility of documentation of the discussion points and observation of the tape. The researcher carried out the FGD in each hospital in privacy, all the rules for conducting FGD were considered, and all points which were discussed were well documented.

In-depth interviews:

In-depth interviews data, observation check lists and the intervention data were all collected by the researcher.

\subsection{Data management and Analysis}

The quantitative data (questionnaire) was checked, vetted and validated after entry and before analysis. The entered data was analyzed Using SPSS version 21 appropriate statistical test was used.

The qualitative data (FGD with the sisters and in-depth interview with the doctors) was analyzed using thematic content analysis.

\subsection{Ethical Considerations}

Ethical approval from SMSB research committee was obtained. Clearance from Sennar state Ministry of Health, Sennar teaching hospital and Singa teaching hospital was obtained. Verbal consent from the participants (nurses, doctors \&sisters) was also obtained.

\section{Results}

\subsection{TNA Quantitative Results}

The results showed that out of 173 nurses, a total 
number of 110 nurses (64\%) were from Sennar Teaching Hospital and 63 nurses (36\%) were from Singa Teaching Hospital. The nurses who participated in the study were $80 \%$ female, while only $20 \%$ were males. Most participants were young, $78 \%$ of whom were between 20 and 30 years of age. Regarding education, 64\% of the respondents received the diploma, 32\% received a bachelor nursing certificate and only $4 \%$ received bridging certificates. In addition, $70 \%$ of the participants have 10 years of work experience and less.

Most of the nurses deal well with most of the equipment; yet, some of them believed that they cannot deal with rectal catheter, pulse oximeter, tape, and tracheotomy set and chest tube (Table 1). The vast majority of nurses did not attend some of the major training courses. The results showed that the percentage of participants who received training in any of the nine basic training was less than $12 \%$, except for basic life support training attended by 21 of the respondents (12\%) (Table 2 ). Although the result indicated that only $1 \%$ of the study participants received training on communication skills, $62 \%$ believe they are performing communication skills excellent in all the tasks assigned to them and have interaction part (table 3). While in average $79 \%$ of the respondents believe that communication skills are very important to do their job, $93.1 \%$ of them perceived 'oral communication' as the extremely important communication skill and $64.2 \%$ of them perceived 'listening' as the one extremely important (Table 4). The nurses' perception of their performance indicates that there are gaps in the application of all tasks but clearly shown in quality and infection control procedures, $50 \%$ and $60 \%$ of them cannot do so and need training respectively (Table $5)$. And (81.4\%) of the nurses appreciated the importance of their tasks (Table 6).

Table 1. Perception of nurses towards their skills in using basic equipment, Sennar State 2016 ( $n=173$ ).

\begin{tabular}{llll}
\hline Equipment & I can use it properly and train others & I can use it properly to do my job & $\begin{array}{l}\text { I don't know how to use it and I need } \\
\text { training }\end{array}$ \\
\hline Sphygmomanometer & $121(70 \%)$ & $48(28 \%)$ & $4(2 \%)$ \\
Stethoscope & $106(61 \%)$ & $51(30 \%)$ & $16(9 \%)$ \\
Weighing scale & $115(67 \%)$ & $53(31 \%)$ & $5(3 \%)$ \\
Canula & $144(83 \%)$ & $27(16 \%)$ & $2(1 \%)$ \\
NG Tube & $106(61 \%)$ & $50(29 \%)$ & $17(10 \%)$ \\
Urinary catheter & $118(68 \%)$ & $42(24 \%)$ & $13(8 \%)$ \\
Rectal catheter & $81(47 \%)$ & $37(21 \%)$ & $55(32 \%)$ \\
Ventilator & $116(67 \%)$ & $49(28 \%)$ & $8(5 \%)$ \\
Nebulizer & $109(63 \%)$ & $41(24 \%)$ & $23(13 \%)$ \\
Safety box & $113(65 \%)$ & $44(25 \%)$ & $16(9 \%)$ \\
Pluseoxmeter & $46(27 \%)$ & $30(17 \%)$ & $97(56 \%)$ \\
Tape & $57(33 \%)$ & $34(20 \%)$ & $82(47 \%)$ \\
Tracheotomy & $34(20 \%)$ & $22(13 \%)$ & $117(67 \%)$ \\
Chest tube & $27(16 \%)$ & $21(12 \%)$ & $125(72 \%)$ \\
\hline
\end{tabular}

Table 2. Training courses attended by nurses in the last 3years, Sennar State $2016(n=173)$.

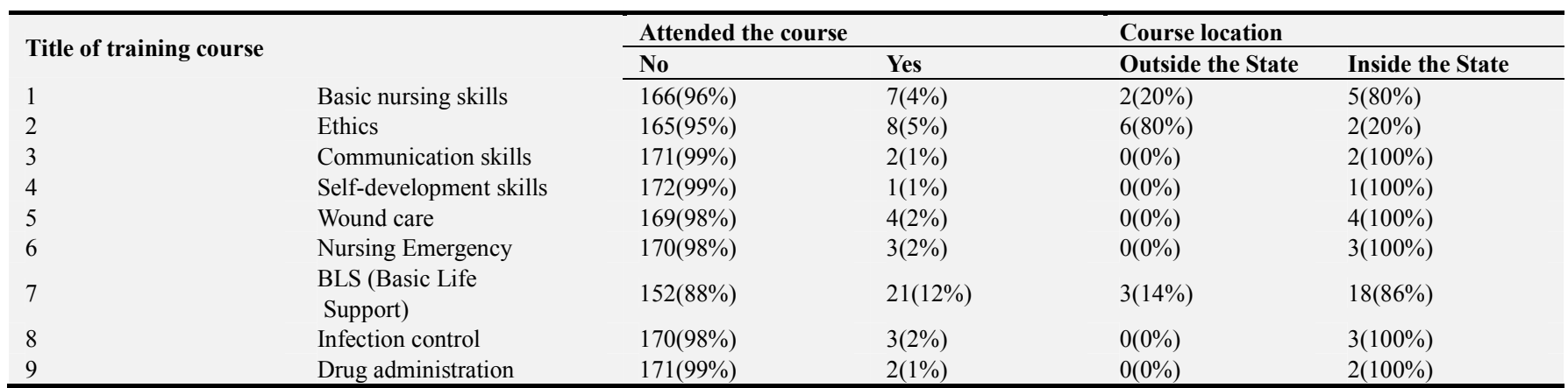

Table 3. Perception of nurses towards their performance in communications skills, Sennar State 2016 ( $n=173)$.

\begin{tabular}{|c|c|c|c|c|c|}
\hline Type of skill & Low & Acceptable & Good & Very good & Excellent \\
\hline Oral communication & $1.2 \%$ & $0.6 \%$ & $2.9 \%$ & $11 \%$ & $84.4 \%$ \\
\hline Written reports & $1.7 \%$ & $1.7 \%$ & $8.7 \%$ & $22 \%$ & $65.9 \%$ \\
\hline $\begin{array}{l}\text { Listening and skills of asking questions } \\
\text { to service recipient }\end{array}$ & $4.6 \%$ & $2.9 \%$ & $5.8 \%$ & $22 \%$ & $64.7 \%$ \\
\hline Team management & $4.0 \%$ & $8.1 \%$ & $11 \%$ & $22 \%$ & $54.9 \%$ \\
\hline Managing meetings efficiently & $8.1 \%$ & $5.8 \%$ & $26 \%$ & $22.5 \%$ & $37.6 \%$ \\
\hline Overall average & $4 \%$ & $4 \%$ & $11 \%$ & $20 \%$ & $62 \%$ \\
\hline
\end{tabular}


Table 4. Perception of nurses towards the importance of communications skills, Sennar State $2016(n=173)$.

\begin{tabular}{|c|c|c|c|c|c|}
\hline Type of skill & 1 & 2 & 3 & 4 & 5 \\
\hline Oral communication & $0.6 \%$ & $0.6 \%$ & $2.3 \%$ & $3.5 \%$ & $93.1 \%$ \\
\hline Writing reports & $1.2 \%$ & $1.7 \%$ & $3.5 \%$ & $9.8 \%$ & $83.8 \%$ \\
\hline Listening and asking questions skills & $5.2 \%$ & $2.3 \%$ & $13.9 \%$ & $14.5 \%$ & $64.2 \%$ \\
\hline Managing meetings efficiently & $3.5 \%$ & $2.9 \%$ & $5.2 \%$ & $10.4 \%$ & $78.0 \%$ \\
\hline Overall average & $3 \%$ & $2 \%$ & $6 \%$ & $10 \%$ & $79 \%$ \\
\hline
\end{tabular}

1=Not important; 2=Moderately important; 3=Important;4=Very important; 5=Extremely important.

Table 5. Nurses' perception towards their performance in nursing tasks, Sennar State, $2016(n=173)$.

\begin{tabular}{|c|c|c|c|c|}
\hline Task & Cannot do it & Can do it but need training & Can do it & Can do it \& train others \\
\hline Basic nursing skills & $2.9 \%$ & $39.9 \%$ & $28.9 \%$ & $28.3 \%$ \\
\hline Drug administration & $2.9 \%$ & $31.2 \%$ & $29.5 \%$ & $36.4 \%$ \\
\hline Wound dressing and minor surgery & $4.6 \%$ & $42.8 \%$ & $24.3 \%$ & $28.3 \%$ \\
\hline Reporting of abnormal signs and symptoms & $1.7 \%$ & $32.4 \%$ & $37.0 \%$ & $28.9 \%$ \\
\hline Urine and stool sample collection & $4.6 \%$ & $32.9 \%$ & $28.9 \%$ & $33.5 \%$ \\
\hline Sterilization of tools and devices & $8.1 \%$ & $40.5 \%$ & $29.5 \%$ & $22.0 \%$ \\
\hline Receiving and dealing with accident and emergency cases & $6.4 \%$ & $34.7 \%$ & $35.8 \%$ & $23.1 \%$ \\
\hline $\begin{array}{l}\text { Patient discharge and giving instructions about how to } \\
\text { continue the treatment especially for the chronic diseases }\end{array}$ & $2.4 \%$ & $30.6 \%$ & $33.5 \%$ & $33.5 \%$ \\
\hline Application of infection control and safety measures & $10.4 \%$ & $39.9 \%$ & $26.0 \%$ & $23.7 \%$ \\
\hline Application of quality control measures & $16.8 \%$ & $42.8 \%$ & $20.8 \%$ & $19.7 \%$ \\
\hline Assisting in training of junior nurses and students & $2.9 \%$ & $37.6 \%$ & $24.3 \%$ & $35.3 \%$ \\
\hline Overall average & $5.5 \%$ & $35.8 \%$ & $29.4 \%$ & $29.3 \%$ \\
\hline
\end{tabular}

Table 6. Nurses' perception towards the importance of nursing tasks, Sennar State, $2016(n=173)$.

\begin{tabular}{|c|c|c|c|c|}
\hline Task & Not important & Moderately important & Important & Very important \\
\hline Basic nursing skills & $0.6 \%$ & $4.0 \%$ & $15 \%$ & $80.3 \%$ \\
\hline Drug administration & $0.6 \%$ & - & $13.3 \%$ & $86.1 \%$ \\
\hline Wound dressing and minor surgery & - & $1.2 \%$ & $17.5 \%$ & $81.3 \%$ \\
\hline Reporting of abnormal signs \&symptoms & - & $1.2 \%$ & $13.9 \%$ & $85.0 \%$ \\
\hline Urine and stool sample collection & - & $1.2 \%$ & $17.3 \%$ & $81.5 \%$ \\
\hline Sterilization of tools and devices & - & - & $16.2 \%$ & $83.8 \%$ \\
\hline Receiving and dealing with accident and emergency cases & - & $1.7 \%$ & $18.5 \%$ & $79.8 \%$ \\
\hline $\begin{array}{l}\text { Patient discharge and giving instructions about how to continue } \\
\text { the treatment especially for the chronic diseases }\end{array}$ & - & $0.6 \%$ & $19.1 \%$ & $80.3 \%$ \\
\hline Application of infection control and safety measures & - & $1.7 \%$ & $17.3 \%$ & $80.9 \%$ \\
\hline Application of quality control measures & $1.2 \%$ & $3.5 \%$ & $18.5 \%$ & $76.9 \%$ \\
\hline Assisting in training of junior nurses and students & - & $0.6 \%$ & $20.2 \%$ & $79.2 \%$ \\
\hline Overall average & $0.8 \%$ & $1.8 \%$ & $16.9 \%$ & $81.4 \%$ \\
\hline
\end{tabular}

The results also revealed that only $5 \%$ of the participants had no idea about nursing ethics. With regard to the training needs identified by the respondents, 61 nurses thought that they need training in the infection control, followed by 59 and 57 nurses who identified basic life support and ICU as their training needsrespectively.

\subsection{TNA Results of FGDs and in-Depth Interviews}

\subsubsection{Qualitative Results of the FGDs with Sister Nurses}

On account of the exploratory nature of the research objective, the study utilized qualitative research methods. Two (FGDs); one group from Sennar and other group from Singa Hospitals; were conducted in November and December 2016. A total of 16 female nurse sisters participated in FGDs each comprising of 8 participants. The participants were purposively selected from the targeted hospitals under the study. The discussions were held in halls within the hospitals.
The discussions were conducted in Arabic by the principal investigator and research assistant and were all of them noted and some of them tape recorded. The discussions lasted between 45 and 60 minutes. Themes that discussed were; tasks performance, performance gaps and training needs. The discussion started with an ice-breaking question on the reasons behind their choice of the nursing profession. Most of the participants justified their choice because they perceive nursing as a humane profession. Some of the participants see nursing as a way to help their communities, while others see it as self-satisfactory job. Participants also listed other reasons such as the influence of some nurses they see them as models, a desire of their families, or an educational opportunity they got through formal enrolment to nursing colleagues.

Sisters' evaluation of skills of nurses in communication:

Nurses need abilities to effectively use communication skills with their patients, colleagues and doctors. One 
sisterclaimed that "communication skills help the nurse to manage her work inside the ward". However, participants highlighted that the majority of nurses had gaps in communication skills, especially young nurses who had limited exposure to communicate with others. As well, the discussion described some of the nurses to have negative attitudes towards dealing with patients, colleagues and doctors. One of the participants argued that "some of the nurses have bad attitude in dealing with patients, and some nurses usually refuse to attend to advises by other colleagues". This is further associated to the respondents' observation that elderly patients are relatively demanding, and so they need special caring and communication style. However, some of the nurses have poor skills in dealing with elderly patients. One of the nurses argued that "elderly patients need nurses with special skills". Another communication problem identified was that nurses don't ask others for information that they don't know. This is situation because some of nurses hold the view that such a query for information may mean that they are less experienced and less knowledgeable; for example, urgent calling and consultation with other health staff (doctors) in the case when a patient has a new complain or develops serious signs. Instead, participants mentioned that such a query is a task performed by co-patients who directly talk to doctors - "co-patients inform the duty-doctor of their patients complain or develop convulsions as an example; this is the nurse job" - one participant said. Communication gap on non-querying for information also exists because some nurses have problems in sharing information with others.

Sisters' evaluation of nurses' basic nursing skills:

Nursing requires several skills, depending on roles and responsibilities identified in job descriptions. This study examined some specific basic nursing skills, namely: (i) drug administration; (ii) wounds dressing and minor surgery; (iii) registration and file keeping of nursing activities; (iv) reporting of abnormal signs and symptoms during duty; and (v) patient discharge and post-discharge instructions and advises. In analyzing the discussions by participants, it is found there is a necessary association between the performance of the above-mentioned basic nursing skills and other issues, such as safety and infection control measures. Findings generally indicate that professional nurses (sisters) who hold bachelor degrees are more competent than nurse technicians who have hold diplomas or departmental certificates. Competency gaps were found most among nurse technicians who normally did not do self-improvement or request support to acquire skills or apply them properly. One sister said that "nurse technicians have fewer experiences than the other nursing staff; for example, when a nurse technician receives a patient, and his/her intravenous treatment may lead to vein rupture and blockage of canola. They don't care to improve their skills". One the basic responsibility of nurses is to ensure appropriate drug administration, including pharmacology, anatomy and physiology, and legal issues. The main skill gaps identified in drug administration were: delays in giving the subscribed doses, non-registration of drug, and lack of close mentoring of patients in the ward so as to meet their needs. Participants admitted that "some nurses delay the doses; some others don't register what they did; and so, patients' files sometimes are not filled in with information in regards to what happened inside the ward". This is further complicated with the nurse workload as a result of the small number of nurses compared to the large number of admitted patients. Another nursing skill gap is that nurses don't follow the management plan properly, before patients are send to the operation room. Nurses don't give patients the regulations and advises correctly. Likewise, they also don't report to the medical director when medical devises are stopped at workplace. According to participants, these gaps exist due to absence of regular supportive supervision.

Participants said that nurses in general have skill gaps in handling wounds and minor surgery but certified nurses are relatively better. This gap further complicated by absence of a system of infection control measures. This requires an application of standard precautions in nursing work, which is lacking, so as to reduce risk of transmission of blood-borne and other pathogens to nurses. Hospitals covered by the study lack prevention measures for HIV transmission. Unavailability of soaps also was found to limit hand-washing among nurses. Participants stressed on raising the staff awareness and avail the resources for applying the quality assurance program. The study found that most of nurses working in wards don't wear gloves, masks and lab-coats, as well as they don't use safety boxes, which are lacking inside the wards in most cases. Participants admitted that "after giving patients intravenous or intramuscular treatment, some of the staff just dispose the syringes on the ward floor without caring for the protection of others". However, nurses revealed diverse level of awareness with regard to infection control measures. A number of nurses were found to be subconscious of hygiene procedures (e.g. hand-washing) and infection control measures. Moreover, they are faced with shortage in availability of personal protection measures. Participants went further to mention that "inside the ward, it is usually difficult to differentiate between working nurses and co-patients, because nurses don't wear lab-coats, for example".

Training of the nursing students:

One of the nurses' tasks in their job description is the training of the nursing students inside the wards so that students are able to practice the acquired skills. Participants mentioned that nurses are good tutors in general. However, some of the nurses do not train students but they rather assign the students and junior nurses to do their tasks so as to reduce the workload. One of the sisters said that "nursing students are faced with problems during the practical training stage; some tutors leave nursing students work without close supervision while requesting them to do work that is assigned to nurses".

Evaluation of commitment to nursing job ethics:

Nursing ethics are a set of moral principles that nurses should follow and commit to when delivering their tasks. The 
nature of the nursing profession is highly dependent on ethical care much more than the routine care. To do so, nurses need to know these ethics that guide their job performance, as well respecting them. The discussion with sisters had revealed various forms of violations of nursing ethics. These violations included carelessness in delivering daily clinical work, escaping during working hours, bad attitude, bad treatment and exploitation of patients by charging extra fees, and selling of emergency drugs that should be provided to patients for free. One of the participants supported some these arguments by saying that "the problem of nurses is that they are careless". Another participant said "some nurses take money from patients for serving them".

Identification of training needs for nurses:

Nursing is a dynamic profession that is subject to rapid changes in health care provision. And so, there are needs for refresher in-service training program for nurses to cope with such changes. As mandated institution, it becomes inevitable for the CPD in Sennar State to conduct in-service training for nurses. The fact is that nurses in Sennar State have been experiencing limited opportunities for in-service training program. One participant mentioned that "some of the nursing staff members are good when they are doing their jobs. But some of them have apparent gaps as still perform their tasks in an 'old way' and so are in need of urgent refresher training". While part of the old nurses need to update and upgrade their knowledge, newly registered nurses require in-service training in order to be skilled in nursing practice. Another nurse said "there is huge gap between what you learn and what the practice in real life; and so newly nurses are in need of training in practical nursing skills". As part of the FGD, the study had a focus on identifying the needs of nurses in relation to in-service training programs, as well as drawing broad guidelines for the development for effective in-service training programs. Based on the focus discussion, participants identified a list of the priority areas that are important to nurses as in-service training programs of Infection control, Communication skills, Ethics of the profession, Basic nursing skills, Training on use of medical equipments especially in the dialysis unit equipment, Basic Life Support BLS. ICU\&CCU, Sterilization of equipment, Discharge instructions/advises, Administration and registration of drugs.

\subsubsection{Qualitative Results of Doctors' in-Depth Interviews}

This study also utilized in-depth interviews with 13 doctors from the targeted hospitals and majority of them were females. The themes discussed were; Knowledge of the concept of Continuous Professional Development; In-service training courses to nursing staff - types, benefits, challenges; proposals for improving the training of nursing staff and Perspectives on training needs of the nursing staff.

Doctors' knowledge of the CPD concept:

Findings of the interviews revealed that doctors in both of the surveyed hospitals (Sennar and Singa) are generally aware of the idea/concept and importance of CPD. However, a small number of the doctors interviewed could not recognize "what CPD is about" although they mentioned that they have heard about. Some doctors know/see the CPD just as an office inside the State Ministry of Health, rather than a widely-known concept. Furthermore, the interviewed doctors have perceived that:(i) a limited number of staff has the interest in receiving in-service training; (ii) some nurses are not interested in self-development in a professional way like that of the CPD; and (iii) some nurses think that they are not in need of additional skills in the post-graduation era. Doctors perceive CPD as an important milestone for career growth, especially after some years of work. Nevertheless, they believe that most of the health cadres in the two hospitals were subconscious of the importance of in-service training and upgrading their skills; CPD in-service training is neglected and had limited activities. The limitation of resources played a main role of its negligence.

Doctors' perspectives of training courses delivered to their nursing staff:

Interviewed doctors had good capturing of the in-service training courses delivered to their nursing staff. They counted at least 7 packages of training on: (1) Basic Life Support; (2) Renal Dialysis Devices; (3) Nursing Emergency; (4) Advanced Life Support; (5) Neonatal Resuscitation; (6) Quarantine, Management and Prevention of Diarrheal Diseases; and (7) Malaria Protocol. However, a small number of doctors could not identify any event of training during the time they have joined the hospital. Impact of these training packages were judged by the doctors as useful in many ways; improvement of the competency and hence the performance of nursing staff in delivering quality services for both cold and emergency cases; better and quick handling of serious cases; nurses are better in detecting serious cases and delivering the appropriate primary aids, which further contributes to reducing mortalities; nurses had major role in controlling the latest outbreak of the diarrheal diseases in the State.

Doctors' perspectives of challenges to training courses delivered:

Interviewed doctors had counted a series of challenges that they perceived to have encountered the training packages/courses delivered to their nursing staff. All doctors unanimously agreed that the major challenges were: (1) problems associated with releasing the nurses so as to enable them to participate in training courses, which mainly due to the shortage of the nursing staff; and (2) the difficulties associated with financing training courses. Other challenges identified by some of the doctors are; lack of trainers, fairness of the selection process, language problem and enabling educational environment.

Doctors' perspectives of challenges to training courses in their institute:

The challenges identified by some of the doctors are; difficulties in obtaining financial support for training courses; lack of well-equipped training halls/ venues; non-releasing of nurses of duties to participate in training courses because of the already small number of staffing; difficulties in 
application. Because sometimes courses were on equipment not available in the workplace; lack of trainers/ facilitators. carelessness of the health cadre about training; improper/ injustice and inequality in selection process of trainees, which implied biasness.

Suggestions to improve the nurses training:

Doctors suggested many opinions about how to improve training in their institutes such as; financial support to the nurses training; provision of skill labs; provision of wellequipped training halls/venues; increase number of facilitators according to the specialty; linking of the training with the career path way/ career progression; creating training opportunities at the universities; provision of curricula; allocation of part of the hospital income for the training; raise the awareness of the managers about the importance of the training.

Areas for the training of nurses suggested by doctors': Infection control; nursing emergency; nursing Ethics; communication skills; drug administrations; basic nursing skills; ICU; training on use of medical equipment especially in the dialysis unit equipment and accountability.

\section{Discussion}

\subsection{Respondents' General Characteristics}

TNA is not very common concept /approach until recently even in the developed countries. The available literature reveals that there has been a significant growth in the number of TNA researches during the period 1990 to 2010 in comparison to the period 1970 to 1989 [8]. For example, TNA for nurses was never conducted before 2014 [7]. However, Sudan is not an exception where TNA research is very rare and requires special attention now and in future. The current study is an attempt to draw attention to the importance of TNA in Sudan for better utilization of the available resources using parametrically valid instruments. To identify the training needs of nurses in Sennar State, this study adopted different methods, using both quantitative and qualitative tools for data collection. Such a technique, known as triangulation, was used to ensure the validity and reliability of results by means of providing different viewpoints to analyze the specific issues from different perspectives [9]. The study started by a 'survey' which was the most common used type for collecting TNA data $[8,10-$ 14]. The common problem identified with such type of survey studies was the low level response since these surveys primarily collect data through e-mails, which might affect the results. But this study was not faced with such a problem because it directly collected data from respondents with high level of response, which was more than $90 \%$.

According to the study findings, the number of nurses in Sennar Teaching Hospital was by far more than those in Singa Hospital Teaching Hospital, respectively 64\% and $36 \%$. This is due to the expansion in Sennar Hospital in terms of addition of new sub-specialty and more number of consultants to become the main Teaching Hospital in the
State, following the establishment of the Faculty of Medicine University of Sennar. Out of 173 nurses who participated in this study, $80 \%$ were females. This result goes with the general pattern of increasing female to male ratio in the health workforce, which is more visible in the case of nurses in Sudan [5]. This gender imbalance in the health workforce requires special planning and policy measures. In terms of age and experience, a total of $78 \%$ of the nurses aged between 20 to 30 years, and $70 \%$ of them had work experience of 10 years and less. Because they are young with limited experience, these nurses represent a good opportunity for investment.

In terms of the level of education, the majority of the participant nurses $(64 \%)$ had diploma certificate, $32 \%$ had nursing certificate, and only $4 \%$ had bridging course certificate. The reason behind this result was related to expansion in the coverage of the Academy of Health Sciences (AHS), which has opened up branches in all states, enrolling estimated number of 15,300 students in the years 2010 out of which $80 \%$ were nursing student [2]. The result could be attributed to the fact that AHS diploma has substituted the old nursing certificate. The 'bridging-course' was another program introduced by the AHS to upgrade the diploma into bachelor degree but the program faced résistance from the Ministry of Higher Education, and had worked for only few years. That was the main reason behind the few nurses with bridging-course certificates.

The largest human resources component in healthcare institutions is apparently nurses, who have the greatest impact on the quality of both outcomes and patient care. As such, training becomes essential so as to achieve successful, tangible and measurable benefits to healthcare institutions. Another importance of training and investment in human resources in general, is retention of the qualified health workers [7].

Based on the study findings, it is apparently that the great majority (95-98\%) of the participant nurses had not attended any of the essential training packages during the last three years preceding the study, although the study's list of training courses are the most essential ones that are mandatory for any nurse. This finding is similar to the results arrived at by Ghada Abd El-Salam Belal who found that about 91\% the participants did not attend any type of training [15], and it is also similar to the result reached by Debbie Robson's study that only $20 \%$ of the participants had received training during the last 5 years preceding the study [12]. But, S. Procter's study found that $95 \%$ of the study participants had received training during the last 3years preceding the study [14].

According to doctors who were interviewed in this study, the only self-funded training course (BLS course) that organized in Sennar State, had faced many challenges, including non-release of nurses to attend the course due to staff shortage, unsuitable training environment, limited announcement / advertising of the training courses to the wider nursing staff, and langue barriers since the BLS's modules were in English. These constraints were more or less similar to what was mentioned in Tessa Pascoe's study [11]. 
Training in Sennar State in general is facing many constrains that need to be addressed. One of the key constrain was the reality that most of the nurses were not aware of the importance of self-development, which could be due to the fact that the idea of CPD and in-service trainings is not well understood by health professionals $[5,16]$.

\subsection{Discussion of Nurses' Skills, Tasks and Performance}

Nurses take the responsibility of dealing with most of the hospital equipment and as such require some basic skills that are critical for dealing with this basic equipment. Findings indicated that the majority of nurses perceived that they are able to use most of the equipment in a proper way, and some believed that they can even train others. However, the deficiency was found to be in using the chest-tube in $72 \%$ of the nurses, $67 \%$ could not deal with tracheotomy, $56 \%$ could not deal with the pulsoxmeter, $32 \%$ could not deal with the rectal catheter, $10 \%$ could not deal with the safety box, and surprisingly that $47 \%$ of the nurses cannot deal with tape. Having asked some of the nurses of the reasons behind inability to use tape, the response was the misunderstanding that such a task is sole responsibility of the nutritionists. All the above identified deficiencies in skills of dealing with basic equipment are critical to be addressed through proper in-service training.

An essential element of nursing care is communication with patients. Nurses' major communication tasks are not only to inform the patient about his / her disease and treatment, but also to generate effective relationship by assessing patients' concerns, showing understanding, empathy, and offering comfort and support to patients [17]. According to findings of this study, participant nurses perceived themselves to have good communication skills in general; $84.4 \%$ of them perceived that they are excellent in oral communication; $65.9 \%$ of them excellent in report writing; a total of $64.7 \%$ of them excellent in listening and asking questions; a total of $54.9 \%$ have excellent team management skills; and 37.6\% thought that they are excellent in managing meetings in an efficient way. In terms of the importance of these communication skills, all nurses perceived these skills as extremely important for performing their job vis-à-vis the essential nursing tasks. It seemed from the nurses' viewpoint that there was no huge gap in relation to their communication skills. However, the sisters had different assessment of the nurses' communication skills. Sisters claimed that nurses have gaps in communication skills, especially the newly recruited nurses who have limited exposure. Sisters described nurses to have harsh communication with patients and co-patients, colleagues and doctors. Another communication problem identified was that nurses in general do not ask others for information that they don't know. All the above-mentioned communication gaps can be addressed through training that should involve sisters and doctors for smooth communication and constructive feedback between colleagues.

The nurses' job descriptions identified by the Sudan Council for Allied Professions include 12 tasks. The study used these tasks to assess nurses' perceptions. Based on the results, it was apparent that nurses' perception was more or less the same as the sisters' opinion with obvious training needs in two tasks areas, namely 'infection control and safety' and 'application of quality measures'.

In complementary to nurses' perceptions about the essential nursing tasks, the nurses were further asked if they had any idea about 'nursing ethics' and whether they apply these ethics in their work or not. Findings indicate that $95 \%$ of the nurses claimed that they know and applied 'nursing ethics' while only $5 \%$ perceived that of them did not know or apply them in their work. This finding was contrary to sisters' argument about nurses' application of the 'nursing ethics'. Generally, when the respondents were asked about moral and ethical issues, their response might tend to the famous respondents' bias of 'consistency motif'. There is a substantial amount of theories and researches suggesting that people try to maintain consistency between their cognitions and attitudes. This tendency of respondents to try to maintain consistency in their responses to similar questions or to organize information in consistent ways is called the 'consistency motif' or the 'consistency effect'. It especially appears in situations when respondents are asked to provide retrospective accounts of their behaviors [18].

\subsection{Nurses' Identified Priority Areas of Training Needs}

As was discussed above, the study findings on nurses' perceptions and performance of essential nursing tasks reveal that the top priority areas centered around the tasks of 'infection control and application of safety measure' and 'quality application'. Having directly asked the nurses of their priority training needs, $61 \%$ of them identified 'infection control and application of safety measures' as their first priority, followed by BLS (59\%) and the ICU training (57\%). The sisters' opinion about the priority areas of nurses' training was in favor of the nursing tasks of 'infection control and application of safety measures' as the first priority, followed by 'communication skills' and then 'nursing ethics'. The doctors identified 'infection control and application of safety measures' as the first priority and an urgent training need, followed by 'nursing emergency, then 'nursing ethics' and finally 'communication skills'. Based the above prioritization by the three groups of participants, this study had selected the consistently agreed area of 'infection control and application of safety measures' as the training 'intervention'. However, it should be noted that training needs are context-specific and are hardly common. For example, Tessa Pascoe's study identified 'communication skills' as priority for $94.1 \%$ of the respondents, 'infection control' was equally a priority for $93.7 \%$ of the same group respondents, and BLS and CPR was third priority for 91.4\%of them [11]. The study by KL University found that 'communication skills' was the least identified training gap [19]. In the study by S Procter, 'infection control' was the second priority need for 44\%, 'equipment training' and 'customer services' were the least priority areas for $24 \%$ and $19 \%$ of the respondents, respectively [14]. 


\section{Conclusions and Recommendation}

This is one of the first researches that used a psychometrically valid tool to conduct TNA for nurses in Sudan. This study has shed light on the real and perceived training needs identified by nurses, sisters and doctors. This paper identified 'infection control and application of safety measures' as the first priority and an urgent training need. These needs should be addressed through proper and evidence-based planning in terms of needs, resources, implementations plan, and close follow-up to assess the impact. Hence, infection control and application of safety measures has been selected as the training intervention which will be dealt with in the second accompanying paper in detail. The qualification of the health workers should by no means be negotiable in as much as they deal with the valuable life of patients. This implies that in-service training in order to qualify health workers should not be compromised along lines of financial constraints or the like. In order to strengthen CPD in Sudan we recommend Federal, State Ministry of Health and CPDD in collaboration with all relevant stakeholders to implement the following recommendations made based on the findings of this study.

At the Federal level

1. Empowerment of federal and state CPD's institutions so as to further spread the concept and culture of CPD to the wider health workforces. This requires visibility and advocacy for the activities of the CPD's institutions.

2. Since it is obvious that the majority of the nurses are females, there is a need for gender-sensitive policy arrangements to attend for the needs of female nurses.

3. Connect the training with the career pathway so that every nurse will have the chance of training, which means that TNA should be part of a routine activity.

4. Incentive for nurses to avoid any possible unethical practice.

5. Reinforce accountability issues for nurses.

6. More researches to capture the TNA for other health cadres.

At the State level,

1. Fair distribution of training chances.

2. High level orientation of relevant authorities about the importance of in-service training.

3. Commitment of hospitals to building the capacity of their staff by allocating special portion of their revenues and/or budget lines for in-serve training.

At the CPDD level,

1. All the training gaps and needs should be considered in developing future modules for the training of nurses in Sennar State.

2. Strengthening of State CPDD to expand its services and outreach.

\section{References}

[1] FMOH, National Human Resources for Health strategic plan 2012-2016. Khartoum: DGHRD 2012.

[2] Badr E, the Academy, of Health Science: present situation and future prospect, Sudanese Journal of Public Health. 2008; 3: 136-139.

[3] FMOH, CPDD Organizational Structure and CPD profile2010 (unpublished).

[4] FMOH, Human Resource for Health Strategic work plan for Sudan. Khartoum: DGHRD. 2007.

[5] FMOH, CPD Policy2006. Khartoum: DGHRD2007.

[6] FMOH, CPD policy 2011. Khrtoum: DGHRD2011.

[7] Mahfod J. Libyan Nurses and Their Training Needs: An Overview and Analysis of TNA as a Tool to Enhance Nurse Learning and Effectiveness. GSTF Journal on Business Review (GBR). 2014; 3(2): 71-79.

[8] Ferreira R. R., Abbad G. Training Needs Assessment: Where We Are and Where We Should Go. BAR, Rio de Janeiro. 2013; 10(1): 77-99.

[9] Yeasmin S, Ferdousour K Triangulation' research method as the tool of Social Science research. BUP journal. 2012; 1(1): 2219-485.

[10] Hennessy D, Hicks C, Hilan A, Kawonal Y, a methodology for assessing the professional development needs of nurses and midwives in Indonesia. Human Resources for Health. 2006; 4(8).

[11] Pascoe T, et. al. The educational needs of nurses working in Australian general practices. Australian Journal of Advance nursing. 2007; 24(3) 33-37.

[12] Robson D, et. al. Mental health nursing and physical health care: a cross-sectional study of nurses' attitudes, practice, and perceived training needs for the physical health care of people with severe mental illness. International Journal of Mental Health Nursing. 2013; 22: 409-417.

[13] Bekkema N. Training needs of nurses and social workers in the end-of-life care for people with intellectual disabilities: a national survey. Nursing Education Today. 2014; 34(4): 494-500.

[14] Procter S, et. al. Practice nurse education needs analysis survey results: Buckinghamshire new university of west London (report) 2016.

[15] Abd El-Salam G, et. al. The educational needs among obstetrical and gynecological nursing ElGharbia Governorate. Journal of Nursing Education and Practice. 2016; 6(4): 84-91.

[16] Rama Devi V, Mallika RaoM. Training needs identification of nursing staff - a case study of a health care organization. Excel International Journal of Multidisciplinary Management Studies. 2012; 2(5): 147-153.

[17] Hashim, S. Evaluation of Role of Continuing Professional Development (CPD) on Job Satisfaction and Retention of Health Workers in two States in Sudan. SMSB. 2013. Unpublished MD Thesis. 
[18] Irma $P$, et. al. Evaluation of communication training programs in nursing care: a review of the literature. Patient Education and Counseling. 2000; 39: 129-145.
[19] Philip M, et. al. Common Method Biases in Behavioral Research: A Critical Review of the Literature and Recommended Remedies. Journal of Applied Psychology. 2003; 88. (5): 879-903. 